\title{
THE DEVELOPMENTAL ANATOMY OF THE AURICLE AND ITS CLINICAL IMPLICATIONS WITH AURICULAR ACUPUNCTURE/AURICULOTHERAPY
}

\author{
C. Bozer* \\ Department of Anatomy, Faculty of Medicine, Trakya University, Edirne, Turkey
}

\begin{abstract}
Auricular acupuncture/auriculotherapy is a treatment based on the detection and stimulation of acupuncture points on the auricle. The embryological hypothesis of ear acupuncture was launched in the 1970's by Bourdiol of France. All organs develop from the foetus's three germ layers, the endoderm, ectoderm, and mesoderm. The ear is one of the few anatomic structures of the human body which is developed from each of these three primary tissue types.

The internal organs except for the heart and the kidneys develop from the endoderm. The endodermal organs are represented in the concha and this part of the ear is innervated mainly by the vagus nerve. The skin, endocrine and nervous systems develop from the ectoderm. These organs are represented in the tail of the helix and the lobule. These parts of the ear are innervated mostly by a branch of cervical plexus. The locomotor and lymphatic systems develop from the mesoderm tissue. These organs are to be found represented in the antihelix, the scapha and fossa triangularis of the auricle. The trigeminal nerve innervates these areas on the auricle.

In the context of these embryological and anatomical knowledge, auricular acupuncture is described with its clinical implications.
\end{abstract}

Key words: auricular, ear, acupuncture, auriculotherapy, anatomy, embryology

\section{INTRODUCTION}

Auricular acupuncture or auriculotherapy are general terms describing all diagnostic and therapeutic approaches using points on the ear. Auricle is accepted as a microsystem in which all organs are represented on the ear. Auricular acupuncture has been practised for more than 2500 years. The oldest record is Huang Di Nei Jing (The Yellow Emperor's Classic of Internal Medicine), written in Chinese, and the oldest Western record is a report by Hippocrates (1-4). In Europe, auricular acupuncture/auriculotherapy has been applied systematically and comprehensively since Doctor Nogier introduced the inverted foetus map in 1957 (3).

\footnotetext{
*Correspondence to: Cüneyt Bozer, Trakya University, Faculty of Medicine, Department of Anatomy, Balkan Campus, 22030, Edirne, Turkey, E-mail: cuneytbozer@trakya.edu.tr,Phone: $+905325956170$
}

Information regarding the entire organism or body part can be retrieved from the ear. There are various explanatory models for how auricular acupuncture works. The embryological hypothesis of ear acupuncture was put forward by Bourdiol in the 1970's. All organs and tissues develop from the foetus's three germ layers, the endoderm, ectoderm, and mesoderm. The ear is one of the few anatomic structures of the human body which is developed from each of these three primary tissue types to be found in an embryo. Paul Nogier first discovered the somatotopic presentation of the human body on the ear and reported that each tissue type in the ear had a link to the various somatotopical reflections and to the innervation related to that part of the ear (Figure 1) (1-4).

With technological improvements, increasingly more clinical trials conducted in the field of 
neuroanatomy, neurophysiology, biochemistry and radiology (fMRI) are presenting evidence regarding the detailed mechanisms of auricular acupuncture/auriculotherapy in the diagnosis and treatment of diseases.

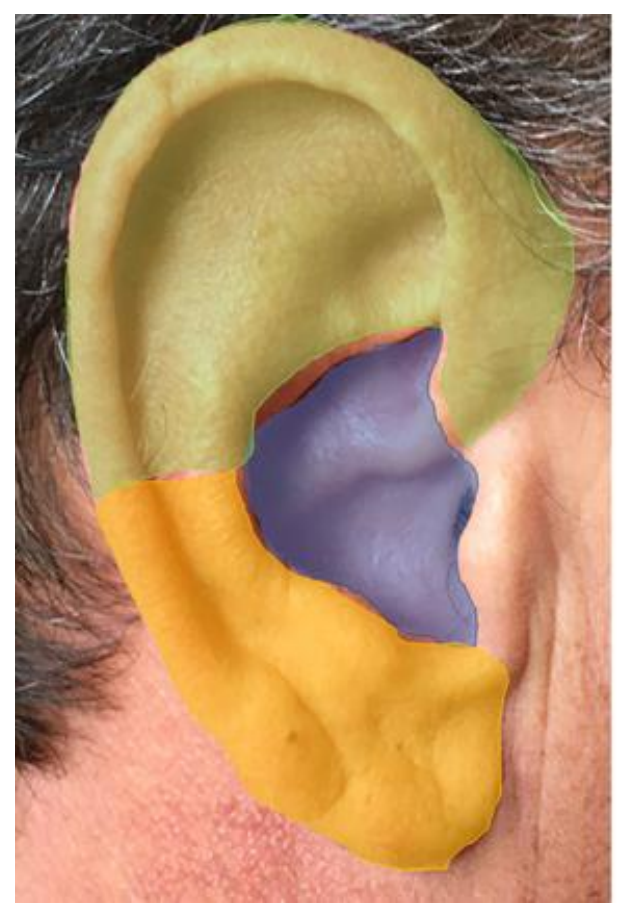

Mesoderm

Endoderm

Figure 1. Ear zones corresponding to the three primary tissue types.

\section{Embryological development of the auricle}

In 1885, His described six auricular hillocks that give shape to the human auricle: three on $1^{\text {st }}$ pharyngeal arch and three on $2^{\text {nd }}$ pharyngeal arch (Figure 2) (5). The auricle develops from these six auricular hillocks derived from the neural crest at the dorsal ends of the first and second pharyngeal arches, on either side of the first pharyngeal cleft (Figure 3 A, B). The hillocks of $1^{\text {st }}$ pharyngeal arch contribute to the tragus and the anterior part of the helix (including the root). The hillocks of $2^{\text {nd }}$ pharyngeal arch contribute to the rest of the auricle including the lobule. Hillock 1 gives rise to the tragus. Hillocks 2 and 3 form the crus of the helix and the helix proper. Hillocks 4 and 5 constitute the anti-helix, and the antitragus and lobule are developed from hillock 6 (5-11). The $1^{\text {st }}$ pharyngeal cleft is between the $1^{\text {st }}$ and $2^{\text {nd }}$ pharyngeal arches. The $1^{\text {st }}$ pharyngeal cleft develops into the external auditory meatus (Figure 4). Defects in the development of 1st pharyngeal cleft can result in preauricular cysts and/or fistulas $(11,12)$.

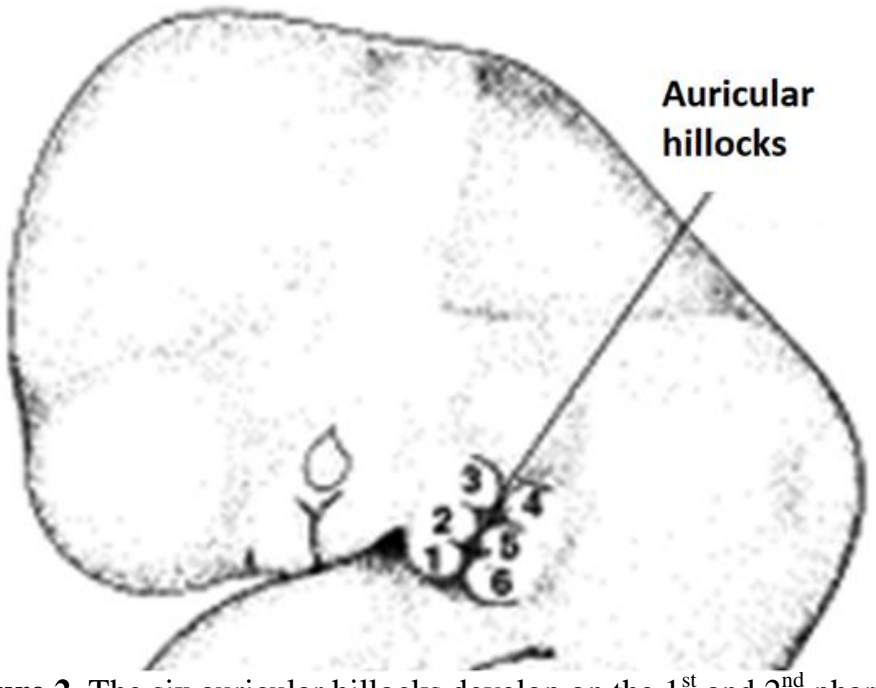

Figure 2. The six auricular hillocks develop on the $1^{\text {st }}$ and $2^{\text {nd }}$ pharyngeal arches at approximately 6 weeks of gestation. 


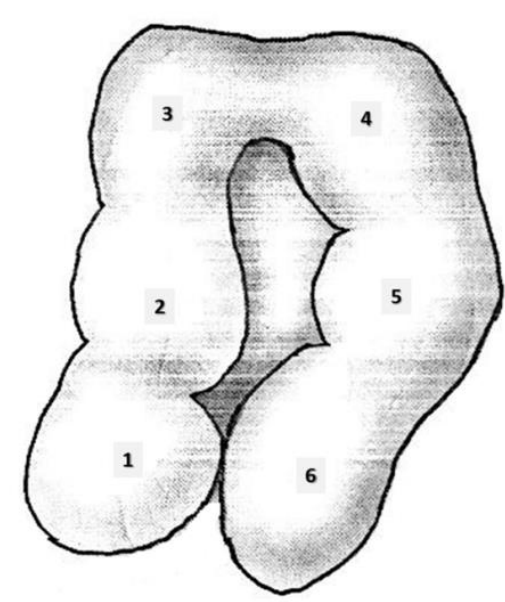

A

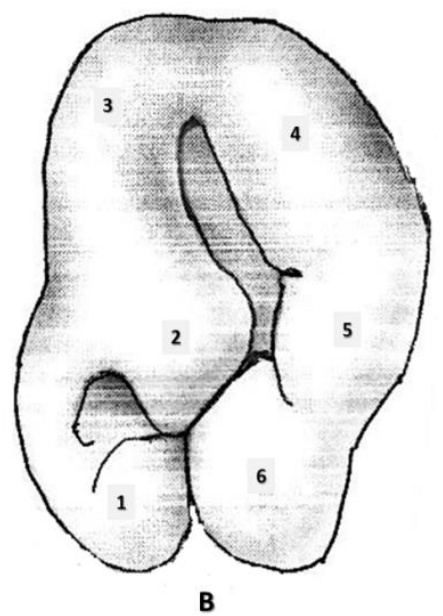

Figure 3, A and B. The hillocks are fusing to form two folds surrounding the first pharyngeal cleft, which will give rise to the external auditory meatus.

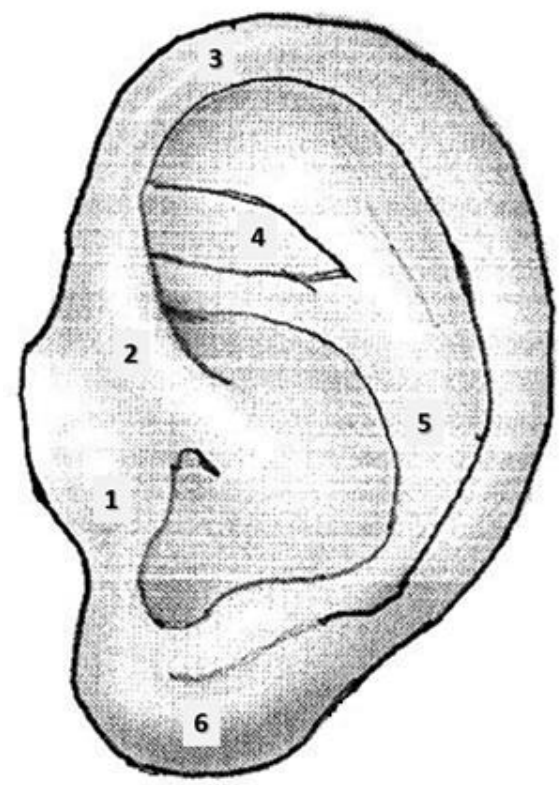

Figure 4. The adult auricle with the derivatives of the six hillocks numbered.

The external ear formed over the course of foetal development, predominantly in 5th week through 20th. Development of the external ear begins at about the fifth week of foetal growth. The auricular hillocks gain maximal prominence by the end of sixth week. In the seventh week, the hillocks undergo directional growth such that they fuse and begin to form the shape of the auricle (5-11).

Pharyngeal arches are formed by cells that are derived from ectoderm, endoderm, mesoderm, and neural crest. The structures of the external and middle ear are made up of endodermal, mesodermal, and ectodermal elements of the $1^{\text {st }}$ and $2^{\text {nd }}$ pharyngeal arches. The external auditory canal is the anatomical remnant of the $1^{\text {st }}$ pharyngeal cleft. Inner ear structures develop from the otic placode (5-11).

A cranial nerve is assigned to each pharyngeal arch. Pharyngeal arches include an aortic arch, a specific cranial nerve and associated muscle, and a cartilage skeleton. The $1^{\text {st }}$ pharyngeal arch is associated with the trigeminal nerve $(\mathrm{CN} \mathrm{V})$, and the $2^{\text {nd }}$ pharyngeal arch is associated with the facial nerve (CN VII) (511). The auricular branch of the vagus nerve $(\mathrm{ABVN})$ is the remnant of a more extensive embryonic nerve which once supplied the first pharyngeal arch (13) and is thought to be derived from nerves supplying the lateral line organs (a system of sense organs used to detect movement, vibration and pressure gradient in 
surrounding water) in aquatic vertebrates, such as fish (14).

At the beginning, the auricles are in the lower neck region, but growth of the body and ramus of the mandible posteriorly and cranially moves the auricles to the side of the head at the level of the eyes. Human ear grows 0,25 $\mathrm{mm} /$ year throughout the entire lifetime (15). Located on the surface of the ear, between epidermis and subcutis, there are around 10000 sensory receptors which make it possible for the ear to be used in diagnosis and treatment. The ear also has a network of arteries, veins, and lymph vessels (16).

The density of nerve fibres in the human auricle compared to other regions of the head seems rather high (17). The great auricular nerve (cervical plexus, C2-C3) supplies the descending helix and the lobule. Organs derived from ectoderm (skin, nervous system) are to be found represented in the part of the ear innervated by cervical plexus. The skin, the brain, the spinal cord, subcortex, cortex and peripheral nerves, pineal gland, pituitary gland, kidney marrow, hair, nails, sweat glands, cornea, teeth, the mucous membrane of the nose, and the lenses of the eye develop from the ectoderm. These organs are represented in the tail of the helix and the lobule. The auricular branch of the vagus nerve supplies the concha. Internal organs derived from endoderm (internal organs, except for kidney and heart) are represented in the part of the ear innervated by the vagus nerve. The auriculotemporal nerve (trigeminal nerve) supplies the ascending helix and superior helix as far as Darwin's tubercle, the triangular fossa, the scapha, the antitragus, and the antihelix including the antihelical wall. The skeletal muscles, smooth muscles, blood vessels, bone, cartilage, joints, connective tissue, endocrine glands, kidney cortex, heart muscle, urogenital organ, uterus, uterine tubes, testicles, blood cells and lymphatic tissue develop from the mesoderm tissue. These organs are to be found represented in the antihelix, the scapha and fossa triangularis of the auricle. The trigeminal nerve connects to the brainstem by the trigeminocervical system with pain blocking impulses for the muscles and skeleton. (Figure 5) (2, 3, 14, 17-20). Motor innervation to muscles of the external ear is supplied by branches of the facial nerve (CN VII) (3).

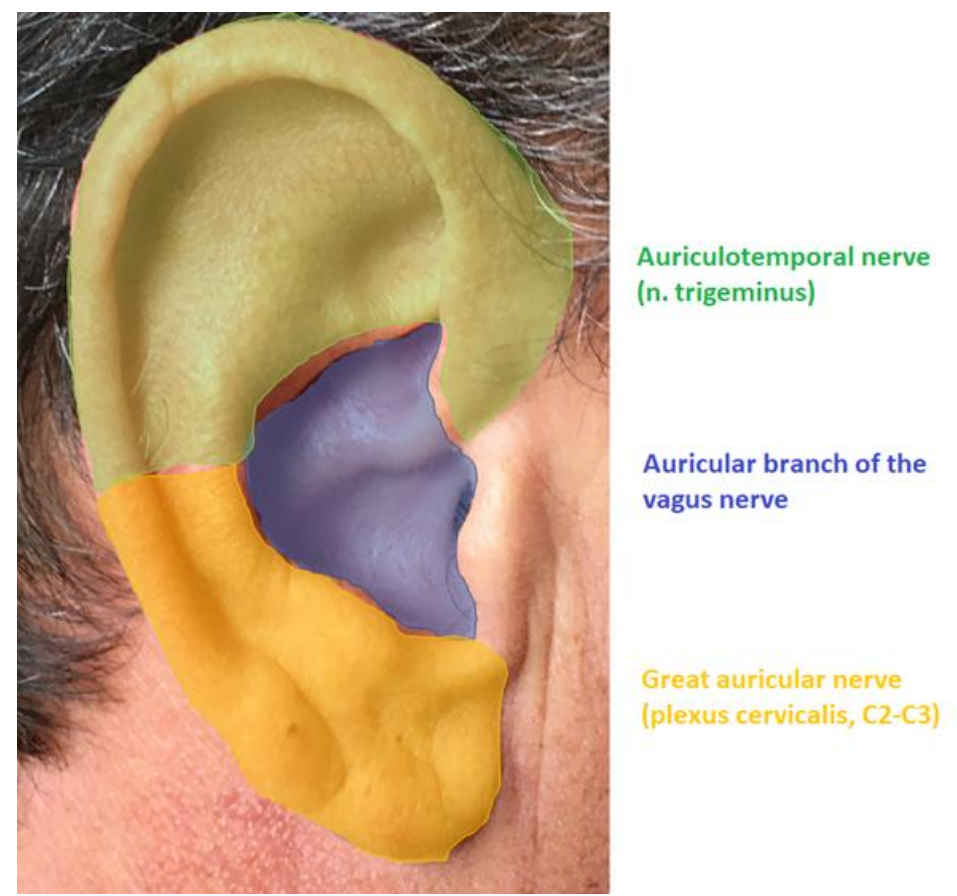

Figure 5. The sensory innervation of the auricle.

\section{Data from fMRI Studies}

Different auricular areas have distinct influence on autonomic functions. Various studies examined the effects of acupuncture stimulation at different auricular areas on autonomic responses. FMRI studies are valuable in terms of demonstrating that auricular stimulation modulates the functional 
state of brain areas. Romoli et al. (2014) employed fMRI to detect the differences between two stimulated acupoints and reported that specificity of auricular acupoints can be assessed by fMRI and that brain responses for the two acupoints tested might be linked to their respective therapeutic indications (21). Alimi et al. (2002) demonstrated that the corresponding point for the hand led to selectively altered fMRI changes in the somatosensory cortex for the hand of the postcentral gyrus (22). FMRI studies of invasive (surgical) vagal nerve stimulation (iVNS) and auricular transcutaneous vagal nerve stimulation (tVNS) have reported activity within the same afferent vagal projection sites (14).

\section{CONCLUSION}

A growing body of literature reports that auricular acupuncture/auriculotherapy exerts therapeutic effects on several disorders and can restore the homeostatic balance in patients. In the light of this, auricles could reveal to be an affordable target for non-invasive manipulation of autonomic and central nervous system functions.

By taking all these data into consideration, future studies on auricular acupuncture will be more significant and will show stronger evidence of its effect.

\section{REFERENCES}

1. Wirz-Ridolfi A. The History of Ear Acupuncture and Ear Cartography: Why Precise Mapping of Auricular Points Is Important. Med Acupunct, 31(3):145- 56, 2019. DOI:10.1089/acu.2019.1349

2. Landgren K. Ear Acupuncture e: A Practical Guide, $1^{\text {st }}$ ed., Elsevier Limited, 2008.

3. Hou PW, Hsu HC, Lin YW, Tang NY, Cheng CY, Hsieh CL. The History, Mechanism, and Clinical Application of Auricular Therapy in Traditional Chinese Medicine. Evid Based Complement Alternat Med, $\quad 2015: 495684, \quad 2015$. DOI: $10.1155 / 2015 / 495684$

4. Nogier R. Auriculotherapy. Georg Thieme Verlag, Stuttgart, Germany, 2009.

5. Veugen CCAFM, Dikkers FG, de Bakker BS. The Developmental Origin of the Auricula Revisited. The Laryngoscope, 00:1-8, 2019. DOI: 10.1002/lary.28456.

6. Tracy, JC., Lee AS., Scott AR., Karmody CS., Embryology and Anomalies of the
External Ear. In: Shiffman MA (ed), Advanced Cosmetic Otoplasty: Art, Science, and New Clinical Techniques. $1^{\text {st }}$ ed., Springer-Verlag, Berlin, Heidelberg, pp 375-384, 2013.

7. Ozeki H. Development of the auricle and external auditory canal. $A d v$ Otorhinolaryngol, 75:30-5, 2014. DOI: 10.1159/000350598.

8. Wright CG. Development of the Human External Ear. J Am Acad Audiol, 8:379-82, 1997.

9. Karmody CS, Annino DJ Jr. Embryology and anomalies of the external ear. Facial Plast Surg, 11(4):251-6, 1995.

10.Siegert R, Weerda H, Remmert S. Embryology and surgical anatomy of the auricle. Facial Plast Surg, 10(3):232-43, 1994.

11.Hunter AG, Yotsuyanagi T. The external ear: more attention to detail may aid syndrome diagnosis and contribute answers to embryological questions. Am J Med Genet A, 135(3):237-50, 2005.

12. Cox TC, Camci ED, Vora S, Luquetti DV, Turner EE. The genetics of auricular development and malformation: new findings in model systems driving future directions for microtia research. Eur J Med Genet, $\quad$ 57(8):394-401, 2014. DOI:10.1016/j.ejmg.2014.05.003

13.Gupta D, Verma S, Vishwakarma SK. Anatomic basis of Arnold's ear- cough reflex. Surg Radiol Anat, 8:217-20, 1986.

14.Butt MF, Albusoda A, Farmer AD, Aziz Q. The anatomical basis for transcutaneous auricular vagus nerve stimulation. J Anat, 236(4):588- 611,

2020.

DOI:10.1111/joa.13122

15.Niemitz C, Nibbrig M, Zacher V. Human ears grow throughout the entire lifetime according to complicated and sexually dimorphic patterns--conclusions from a cross-sectional analysis. Anthropol Anz, 65(4):391- 413, 2007.

16.Roberts A, Sithole A, Sedghi M, Walker CA, Quinn TM. Minimal adverse effects profile following implantation of periauricular percutaneous electrical nerve field stimulators: a retrospective cohort study. Med Devices (Auckl), 9:389-93, 2016.

17.Peuker ET, Filler TJ. The nerve supply of the human auricle. Clinical Anatomy, 15(1):35-7, 2002. DOI: 10.1002/ca.1089. 
18. Rabischong P, Terral C. Scientific Basis of Auriculotherapy: State of the Art. Med Acupunct, 26(2):84- 96, 2014. DOI:10.1089/acu.2014.1038

19. He W, Wang X, Shi H, et al. Auricular acupuncture and vagal regulation. Evid Based Complement Alternat Med, 2012:786839, 2012. DOI: $10.1155 / 2012 / 786839$

20. Mercante B, Ginatempo F, Manca A, Melis F, Enrico P, Deriu F. Anatomo-Physiologic Basis for Auricular Stimulation. Med
Acupunct, $\quad 30(3): 141-50, \quad 2018$. DOI:10.1089/acu.2017.1254

21.Romoli M, Allais G, Airola G, et al. Ear acupuncture and fMRI: a pilot study for assessing the specificity of auricular points. Neurol Sci, 35(Suppl 1):189- 93, 2014. DOI:10.1007/s10072-014-1768-7

22. Alimi D, Geissmann A, Gardeur D. Auricular acupuncture stimulation measured on fMRI imaging. Medical Acupuncture, 13(2):18-21, 2002. 